Because some patients would have aborted in very early pregnancy before being seen for booking at the antenatal clinic they were inevitably excluded from this study. Consequently, our results cannot be interpreted as being representative of the relation between abortion and retroversion in very early pregnancy.

Our findings suggest that retention of urine caused by the retroverted gravid uterus is uncommon. The reason for this is not clear, but Jeffcoate ${ }^{b}$ has suggested that it may be related to the fact that now fewer women are seen with a severe degree of pelvic contraction. Our study did not show an association between retroversion of the uterus and a history of previous infertility. On the contrary, the significantly higher incidence of previous pregnancies in the retroverted group is presumptive evidence of an association between increasing parity and a tendency to retroversion of the uterus. The retroverted gravid uterus clearly does not affect the incidence of urinary tract infection, hyperemesis gravidarum, ante-partum haemorrhage, premature labour, or "light-for-dates" babies.

Our findings suggest that a more cautious approach should be adopted in the management of patients with a retroverted gravid uterus. If seen in early pregnancy advice on sleeping posture, avoidance of intercourse, and frequent emptying of the bladder may be given, and they should be seen again before the end of the 14th week of pregnancy to ensure that anteversion has occurred. Bimanual manipulation should not be performed when the pregnant uterus is retroverted, as our results show that these patients are already at risk. To correct manually the retroverted gravid uterus may only increase the risk of abortion, especially if any force is required. This contention can be confirmed only by a prospective random study.

We thank Mr D Prysor-Jones, Professor J M Beazley, and Mr J R Sutherst for allowing us to study their patients. We also thank other members of the staff who helped us to compile the data, and $\mathrm{Mr} \mathrm{C}$ West of the department of biostatistics, University of Liverpool, who kindly helped with the statistical analysis.

\section{References}

1 Brackett, E S, American fournal of Obstetrics and Gynecology, 1948, 55,184. 2 Javert, C T, American fournal of Obstetrics and Gynecology, 1947, 53, 896. ${ }^{3}$ Moir, C, and Myerscough, P, Munro Kerr's Operative Obstetrics, 8th edn, p 457. London, Balliere, Tindall and Cassell, 1971.

${ }^{4}$ Fouracre Barns, H H, British Medical fournal, 1947, 1, 169.

5 Donald, I, Practical Obstetric Problems, 4th edn, p 216. London, LloydLuke, 1969.

${ }^{6}$ Jeffcoate, T N A, Principles of Gynaecology, 3rd edn, p 354. London, Butterworth, 1967.

\title{
Lysozymuria in diabetes
}

\author{
M FARR, E N WARDLE, K WILKINSON
}

British Medical fournal, 1976, 1, 624-625

\section{Summary}

A reversible lysozymuria indicative of proximal tubular damage to the kidney was found in three out of five patients with diabetic ketosis, and a persistent lysozymuria was found in many patients with diabetic nephropathy. There was no relation between lysozymuria and the degree of proteinuria, and lysozymuria was not due to urinary tract infection. The degree of lysozymuria could be used to assess the severity of diabetic nephropathy.

\section{Introduction}

Urinary lysozyme excretion is used as a measure of dysfunction of the proximal tubules of the kidney ${ }^{12}$ because lysozyme, with a molecular weight of 15000 daltons, is normally filtered at the glomeruli and reabsorbed in the proximal tubules. Only if there is a raised serum concentration owing to release from white cells $^{3}$ or damage to the renal tubular epithelium ${ }^{4}$ does excess lysozyme appear in the urine.

The kidney in diabetic nephropathy presents a difficult problem to the renal investigator. Diabetic nephropathy is

\footnotetext{
Department of Medicine, Royal Victoria Infirmary, Newcastle upon Tyne NE1 4LP

M FARR, MB, MRCP, research fellow (now consultant nephrologist, Hull Royal Infirmary, Hull)

E N WARDLE, MD, MRCP, senior registrar (now locum physician, Sunderland General Hospital, Sunderland)

K WILKINSON, technician
}

partly a specific lesion due to basement membrane thickening, as in diffuse intercapillary glomerulosclerosis or the nodular Kimmelstiel-Wilson disease, but there is also arteriosclerosis and atherosclerosis leading to ischaemic damage to the glomeruli and tubules. It is generally accepted that proteinuria, slowly increasing in severity over the years, is the simplest clinical index of nephropathy. Certainly patients with the heaviest proteinuria have the worst prognosis. ${ }^{5}$

We were interested to examine the incidence of lysozymuria in diabetic nephropathy to see whether it could be related to any of the other indices of renal malfunction.

\section{Methods}

Samples of urine and blood were obtained for estimation of serum and urinary lysozyme and serum and urinary creatinine so that we could calculate a lysozyme:creatinine ratio, as described by Barratt and Crawford. ${ }^{2}$ At the same time a 24-hour urine sample was collected for protein estimation. Samples were obtained from 35 patients with diabetic nephropathy, all of whom had had a renal biopsy and a thorough examination of the retina as part of a therapeutic trial; 68 estimations were performed on samples from these 35 patients. Samples were also obtained from 15 patients with chronic pyelonephritis, 45 patients with a variety of types of nephritis, and seven patients with myeloma. Twenty normal volunteers and 20 diabetics without proteinuria also gave samples. We also performed serial studies on five patients with diabetic ketosis until their recovery.

The lysozyme was estimated by our modification ${ }^{6}$ of the method of Harrison. ${ }^{1}$ This was done by using Micrococcus lysodeikticus as substrate (Sigma Ltd) and using as comparison a standard curve with dilutions of lysozyme at concentrations of $10,5,4,3,2$, and $1 \mathrm{mg} / \mathrm{l}$.

\section{Results}

The figure shows the absolute levels of urinary lysozyme in the various groups of patients. A urinary concentration over $2.0 \mathrm{mg} / \mathrm{l}$ was 


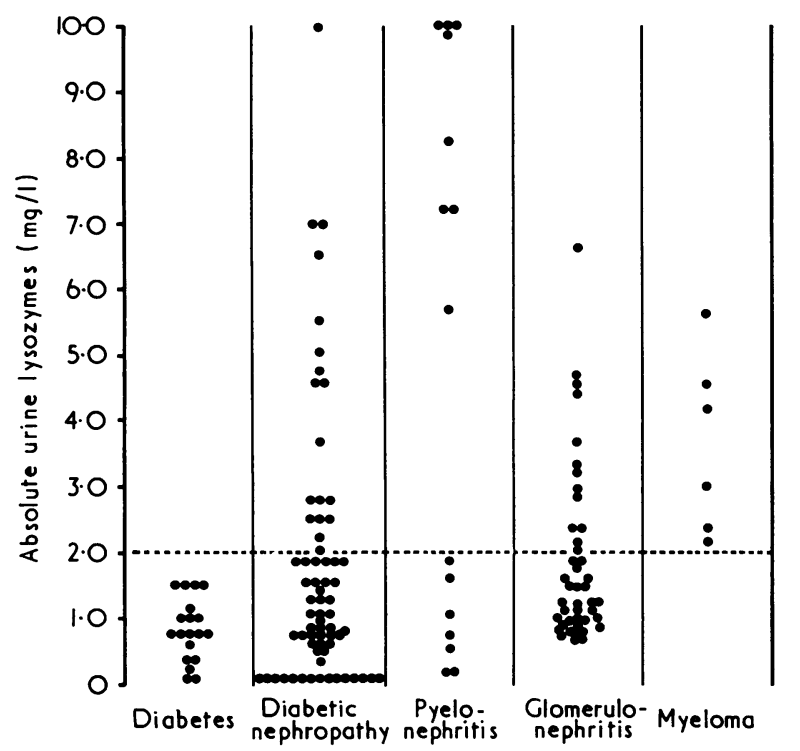

Level of urinary lysozyme in normal diabetics, diabetics with nephropathy, and patients with chronic pyelonephritis, glomerulonephritis, and myeloma. Horizontal line represents upper limit of normal.

considered abnormal. On this criterion lysozymuria indicative of proximal tubular damage was present in 18 of the 68 samples from patients with diabetic nephropathy, whereas there was no abnormality in the 20 diabetic controls without evidence of nephropathy. Eight of the 15 patients with chronic pyelonephritis and 13 of the 45 with nephritis had abnormal levels. All seven patients with myeloma had lysozymuria. Those patients with pyelonephritis who were abnormal were distinctly so, since their urinary lysozyme levels were over $5.0 \mathrm{mg} / \mathrm{l}$

The table shows the same results expressed as the clearance of lysozyme to creatinine. Values from 20 normal people were in the range 0.4 to 4.0 units. Twenty-six estimations on the 20 diabetics without proteinuria gave values in the range $0.7-7.0$ units, but the results from the patients with nephropathy ranged from 3.0 to 250 units. Only 20 ratios were calculated on patients with nephritis but most of these were above the normal range. Again the seven patients with myeloma gave distinctly abnormal values.

The patients with nephropathy had routine mid-stream urine cultures for bacteria, but no patient had a urinary infection during the study. The degree of lysozymuria bore no relation to the degree of proteinuria. Nevertheless, patients with raised serum creatinine values were those with the higher levels of lysozymuria.

During the study it became apparent that another question to be answered was whether there could be an increased release of lysozyme from white cells in the diabetics. Serum levels were always normal and the outpatient diabetic control was good. The problem was examined further by performing serial studies on five patients admitted with diabetic ketosis. At the time of ketosis average serum levels were $5 \cdot 5-6.5 \mathrm{mg} / \mathrm{l}$, falling during the period of treatment and rehydration to $1.5-3.0 \mathrm{mg} / \mathrm{l}$. Normal serum levels are about 3.0 $7 \cdot 0 \mathrm{mg} / 1$. Examination of serial changes in the urinary lysozyme: creatinine clearance ratio during ketosis, however, showed raised values falling towards the normal range in three of the five patients. Thus there was evidence of tubular dysfunction during the period of diabetic ketosis.

\section{Discussion}

The figure shows that about $30 \%$ of diabetics with proteinuria had impaired reabsorption of lysozyme in the proximal tubules of the kidney. A similar proportion of patients with glomerulonephritis had lysozymuria. Indeed tubular dysfunction by vascular insufficiency resulting from the immunological lesion of nephritis is recognised.?

The use of the lysozyme:creatinine clearance ratio discriminates much better (see table). By using absolute urine values only eight out of 15 patients with chronic pyelonephritis were picked out as abnormal, but using the lysozyme:creatinine index all gave abnormal results. Again evidently more patients with diabetic nephropathy or nephritis were recognised as abnormal by the use of the index.

Urinary lysozyme: creatinine ratios

\begin{tabular}{|c|c|c|c|c|c|}
\hline \multicolumn{3}{|l|}{ Category } & $\begin{array}{c}\text { No of } \\
\text { estimations }\end{array}$ & Mean ratio & Significance \\
\hline $\begin{array}{l}\text { Normal . } \\
\text { Chronic pyelonephritis } \\
\text { Diabetes . . .. } \\
\text { Diabetic nephropathy } \\
\text { Glomerulonephritis.. } \\
\text { Myeloma .. . }\end{array}$ & $\begin{array}{l}\ldots \\
\cdots \\
\cdots \\
\cdots\end{array}$ & $\begin{array}{l}\ldots \\
\because \\
\because \\
\ldots\end{array}$ & $\begin{array}{r}20 \\
15 \\
20 \\
35 \\
20 \\
7\end{array}$ & $\begin{array}{l}1 \cdot 48 \pm 0.96 \\
51 \cdot 9 \pm 41 \cdot 5 \\
2 \cdot 58 \pm 2 \cdot 0 \\
37 \cdot 6 \pm 13 \cdot 0 \\
17 \cdot 4 \pm 11 \cdot 8 \\
59 \cdot 5 \pm 35.0\end{array}$ & $\begin{array}{l}<0.05 \\
<0.005 \\
<0.05 \\
<0.05\end{array}$ \\
\hline
\end{tabular}

Although Harrison et $a l^{4}$ have described lysozymuria with hypokalaemia, electrolyte depletion, or postoperative collapse, this is the first report of lysozymuria occurring as a result of diabetic ketosis. It is no doubt consequent on a metabolic disturbance of the cells of the proximal tubule.

The lysozymuria of the patients with diabetic nephropathy must also indicate some dysfunction of the proximal tubules, probably due, as in the nephritides, to vascular insufficiency. No correlations could be established with instability of diabetes, the degree of proteinuria, or the presence of - urinary tract infection, although it is well known that chronic pyelonephritis can produce lysozymuria ${ }^{8}$ It is worth recalling that the lysozymuria of chronic pyelonephritis also does not correlate with the severity of pyuria or with proteinuria or overall impairment of renal function. In our patients with diabetic nephropathy, however, there was some tendency for patients with the highest serum creatinine levels to have the greatest degree of lysozymuria.

Lysozymuria in patients with myeloma was likewise due not to raised serum levels, as is the case in monocytic leukaemia, but to impaired renal tubular function. Since, on rare occasions, a Fanconi-type syndrome may result from myeloma, and renal tubular acidosis may complicate dysglobulinaemias, the finding is of interest but not unexpected.

Diabetic nephropathy is a refractory problem and any new finding may in the long-term be of use in the follow-up of such cases.

We thank Dr P R Uldall for access to these cases and Dr G O Richardson for his help.

Requests for reprints should be addressed to Dr E N Wardle, Department of Medicine, Royal Victoria Infirmary, Newcastle upon Tyne NE1 4LP.

\section{References}

1 Harrison, J F, et al, Lancet, 1968, 1, 371.

2 Barratt, T M, and Crawford, R, Clinical Science, 1970, 39, 457.

${ }^{3}$ Crowder, J G, and White, A C, American fournal of the Medical Sciences, $1968,255,327$.

${ }^{4}$ Harrison, J F, Parker, R W, and de Silva, K L, fournal of Clinical Patho$\log y, 1973,26,278$

5 Watkins, P J, et al, Quarterly fournal of Medicine, 1972, 41, 437.

6 Wardle, E N, British Medical fournal, 1973, 2, 518.

' Favre, H, Wauters, J P, and Mach, R S, Advances in Nephrology, 1971, 1, 195.

8 Hayslett, J P, Perillie, P E, and Finch, S C, New England fournal of Medicine, 1968, 279, 506 . 